Coloquio internacional: «Las sociedades indígenas entre clasificaciones etnográficas y memoria colectiva (época colonial-principios del siglo xx/ siglo $\mathrm{xxi}$ )»

\title{
Gérard Borras
}

\section{OpenEdition}

Journals

Edición electrónica

URL: http://journals.openedition.org/bifea/4094

DOI: 10.4000/bifea.4094

ISSN: 2076-5827

Editor

Institut Français d'Études Andines

Edición impresa

Fecha de publicación: 1 agosto 2013

Paginación: 301-306

ISSN: 0303-7495

Referencia electrónica

Gérard Borras, "Coloquio internacional: «Las sociedades indígenas entre clasificaciones etnográficas y memoria colectiva (época colonial-principios del siglo xx/siglo xxi)» », Bulletin de l'Institut français d'études andines [En línea], 42 (2) | 2013, Publicado el 08 agosto 2013, consultado el 07 noviembre 2020. URL : http://journals.openedition.org/bifea/4094 ; DOI : https://doi.org/10.4000/bifea.4094

Les contenus du Bulletin de l'Institut français d'études andines sont mis à disposition selon les termes de la licence Creative Commons Attribution - Pas d'Utilisation Commerciale - Pas de Modification 4.0 International. 


\section{Eventos}

\section{COLOQUIO INTERNACIONAL: «LAS SOCIEDADES INDÍGENAS ENTRE CLASIFICACIONES ETNOGRÁFICAS Y MEMORIA COLECTIVA (ÉPOCA COLONIAL-PRINCIPIOS DEL SIGLO XX/SIGLO XXI)»}

\section{Rennes, 21-23 de marzo de 2013}

Este coloquio tuvo lugar en Francia, en la Universidad de Rennes2, y fue organizado por Christophe Giudicelli, miembro de la UMR 6258 Cerhio (Centro de investigaciones históricas del Oeste) y del grupo Chacal (Collectif historique et d'anthropologie comparée en Amérique Latine). Contó con el apoyo de diferentes estructuras como la Región Bretaña, la alcadía de Rennes, el Instituto de las Américas nacional y el Instituto de las Américas de Rennes. Viendo el interés de las temáticas propuestas y un deseo de hacer más presentes sus acciones en Francia, el IFEA quiso auspiciar el evento y fue representado por su director. El jueves 21, Christophe Giudicelli abrió el coloquio y delineó los diferentes argumentos científicos del evento.

Este coloquio apuntaba a estudiar, en una perspectiva comparativa que mezcla enfoques históricos, arqueológicos y antropológicos, la formación de «grupos étnicos» entre el periodo colonial y las primeras décadas del $X X$, en varios países de Hispanoamérica. La candente actualidad de las reivindicaciones autóctonas y de las cuestiones - a menudo contradictorias - de patrimonialización y exotización de los indígenas en los países considerados imponía prolongar una reflexión a las mutaciones de este proceso, e integrando al periodo muy contemporáneo. Se constata en efecto que los conflictos y tensiones actuales se apoyan explícitamente en la sedimentación taxonómica anterior.

Según lógicas y modalidades de distintas índoles, la potencia colonial española y luego, después de las independencias, las jóvenes repúblicas latinoamericanas, implementaron unas políticas y un marco legislativo específico para las poblaciones indígenas, para controlarlas e incorporarlas en los diferentes regímenes de producción locales y regionales. Para ello, desarrollaron sistemas y prácticas de 
clasificación, así como políticas de encasillamiento que indujeron transformaciones radicales en las sociedades en cuestión.

Se trataba por lo tanto, en este encuentro, de reconstruir los sucesivos estratos de producción de esas taxonomías, tratando de develar sus lógicas.

Se privilegiaron los puntos siguientes:

- El estudio de las lógicas y prácticas de los diferentes agentes y entidades colectivas implicados (administradores coloniales, misioneros, sociedades científicas, naturalistas, responsables políticos nacionales y regionales, curadores y responsables de colecciones museales...).

- La recuperación y readaptación por parte de las comunidades indígenas de los dispositivos implementados en el marco de esta operación heterónoma.

- El estudio de la «lucha de clasificación» actual y de los intereses concretos y simbólicos que movilizan, en el contexto del multiculturalismo neoliberal y del fuerte resurgimiento de reivindicaciones indianistas desde los años 1990. Se privilegiarán los estudios de caso dedicados tanto a las políticas oficiales de patrimonialización/exotización de los indígenas como las iniciativas tomadas por las comunidades en cuestión para retomar el control de sus tierras y de su patrimonio.

Para llevar a cabo estas diferentes reflexiones se reunieron a 21 investigadores, 9 de los cuales llegaron de diferentes países de América Latina. Se organizaron seis sesiones que permitieron dar elementos de repuesta a la problemática general. La primera fue dedicada al tema de las clasificaciones y producción de categorías coloniales. Jimena Obregón Iturra (Cerhio-Chacal) analiza esta cuestión a partir de un caso concreto, el de la familia Guala en Chile en los años 1683-1707. Dos hermanos, del mismo padre, de la misma madre, apresados por indios «enemigos» después del levantamiento general de 1655, posteriormente a su reintegración y retorno al norte del Bío-Bío terminaron siendo legalmente encasillados en categorías dispares. La incoherente anomalía de resoluciones judiciales opuestas llevó a remitir el caso a las instancias peninsulares para que la decisión regia dirimiera la contradicción. El caso es ejemplar para reflexionar sobre las dinámicas judiciales que retoman e interpretan definiciones jurídicas, consagrando derechos y dictaminando deberes en las personas y grupos así determinados por el orden colonial, imperante al norte del Bío-Bío. Andrés Castro Roldán (Erimit-Rennes2), en su ponencia presentó el caso de los indígenas de la frontera nororiental del Nuevo Reino de Granada, entre los siglos XVI y XVII. Se concentró en particular en dos de las etnias más representativas de este periodo histórico: los Guahibos y los Achaguas, que aparecen siempre en los documentos y en las crónicas jesuitas como diametralmente opuestas. El objetivo era identificar los parámetros en los que se basa esta oposición y determinar en qué medida aquella se encuentra relacionada con los sistemas de ordenación del aparato colonial.

La mesa siguiente tuvo por título «Los Indios entre construcción del estado y control del territorio». Guillermo Wilde (Conicet-Unsam-Idaes), en su ponencia «Territorialización y etnogénesis guarani en el cono sur: del relato jesuita a la 
antropología moderna» se centró en el uso que hacen los religiosos jesuitas en sus documentos oficiales de clasificaciones étnicas (y lingüísticas) homogeneizadoras con objeto de organizar a la población y al territorio, lo que frecuentemente contrastaban con la realidad de heterogeneidad interna efectivamente existente en los pueblos de indios, evidenciada en documentos locales de menor circulación. Capucine Boidin (IHEAL-Paris3) presentó el resultado de una investigación sobre un análisis de cartas escritas en guaraní y español en los cabildos de las misiones jesuíticas del Paraguay entre 1753 y planteó que el guaraní usado en esas cartas es particular y que pertenece a un middle ground linguístico que rompe con las categorías habituales. Silvia Ratto (Conicet-U. de Quilmes) presentó una ponencia sobre «Los indios del Chaco en el siglo XIX: de peligrosos enemigos a potenciales trabajadores» que muestra cómo los habitantes del Chaco fueron un elemento esencial de la actividad económica en la agricultura de la región chaqueña.

La primera mesa del viernes tocó el tema de las relaciones entre sociedades indígenas y la formación de las identidades nacionales y regionales. Claudia Briones del CONICET en Argentina analizó el tema de la legitimidad de las demandas y acciones indígenas en Patagonia que se discute recursivamente en los principales medios de comunicación regionales y nacionales y que movilizan argumentos y luchas clasificatorias sin fin. Evidenció también que los argumentos esgrimidos por los académicos resultan irrelevantes para definir el debate.

Julio Esteban Vezub (Cenpat-Conicet) analizó caso «tehuelche» como uno de los que mejor se ajusta a lo que cualquier corriente antropológica reconocería como un «grupo étnico» en la más general de las acepciones. Propuso una revisión crítica doble, tanto de la etnología culturalista como de la refutación desde el paradigma de las «identidades impuestas» evidenciando que para el caso de la Patagonia no se vio sino clasificaciones aparatosas y rotulaciones étnicas atribuibles a las ficciones de los colonizadores y sus continuadores los antropólogos.

En la tarde se debatió sobre las implicaciones políticas del patrimonio indígena. Mónica Montenegro, de la Universidad Nacional de Jujuy-Tilcara e invitada de la Cátedra de las Américas-IDA-Rennes mostró los efectos de las políticas de patrimonialización en la zona de la quebrada de Humahuaca en Jujuy. En este contexto se producen reapropiaciones de las evidencias materiales de culturas prehispánicas y «aquellas ruinas de un pueblo muerto» hoy son resignificadas por las comunidades originarias como legados ancestrales y potenciales recursos de desarrollo económico para este sector de los Andes Centro Sur. La autora compartió interrogantes que surgen acerca del rol de la arqueología en la construcción de discursos sobre el pasado y el patrimonio, en un complejo contexto donde se imbrican activaciones patrimoniales, mediación científica, emergencia y visibilización de identidades étnicas y reconfiguración de territorios.

Alejandra Korstanje, CONICET-Instituto de Arqueología y Museo, Universidad Nacional de Tucumán y Marisa Lazzari, de la Universidad of Exeter reflexionaron en su presentación sobre algunos de los conceptos que la Arqueología utiliza o ha definido en un contexto que se presumía neutral y que han sido recientemente objeto de adaptaciones, modificaciones (o rechazos) en el marco de las prácticas 
de identidad nativas y sus luchas por el reconocimiento en el espacio público. Algunas de las experiencias ilustrarán los riesgos que nuestras arqueotaxonomías tomadas como capital académico, neutral y respetado traen aparejadas, para la vida de las personas, objetos y paisajes.

En su ponencia Marie-Laure Guilland, ERSIPAL-CREDA-IHEAL (UMR 7227) mostró cómo en un contexto de reapropriación de los objetos y sitios arqueológicos la producción de conocimientos científicos da una nueva función a la disciplina y a sus resultados. Estos, favorecen hoy una interpretación frecuentemente simbólica por parte de las sociedades locales y contribuye a la elaboración de un sentimiento de identidad tan fuerte y real como los objetos que se supone lo simbolizan. Esta nueva realidad cambia de manera muy significativa las relaciones entre y dentro de las comunidades científicas e indígenas cuando se trata del porvenir del patrimonio y de la actividad turística en los sitios arqueológicos de las comunidades.

La ponencia de Violeta Ramírez, Mascipo-EHESS (UMR 8168) toca un tema similar en la zona de Quilmes en Argentina. Un movimiento de pobladores que lucha por el derecho a la tierra deviene una Comunidad que recupera el etnónimo del pueblo de Quilmes y lleva adelante un proceso de reconstrucción de los lazos comunitarios y de las formas culturales indígenas presentes ya en la zona. Este proceso de reconstrucción de etnicidad se da en el marco de promoción de los derechos indígenas a nivel internacional, nacional y provincial. El proceso de lucha por la restitución de su patrimonio arqueológico se enmarca en este proceso más amplio de recuperación del legado indígena y de rescritura de su historia.

En esta misma zona, Maite Boullosa-Joly, mostró cómo podían evolucionar las identificaciones en función de los proyectos desarrollados por las propias comunidades: turismo cultural, étnico. La identidad «india» rechazada y vivida como degradante en décadas anteriores viene a ser recuperada y asumida en épocas recientes.

Paola Bolados de la universidad Católica del Norte, San Pedro de Atacama, a través de fuentes históricas y etnográficas mostró las relaciones y complejidades actuales de la sociedades andinas como la atacameña en el norte de Chile, problematizando sobre los dispositivos de poder bajo las cuales han emergido clasificaciones geográficas como el «Desierto de Atacama», así como las históricas y etnográficas como son las recuperadas y reconfiguradas bajo las adscripciones de «Atacamas»y «Atacameños» en los procesos de revitalización étnica de finales del siglo XX y comienzos del siglo XXI. Estas categorías se analizaron desde una perspectiva de lo trans-nacional para entender mejor los impactos que durante más de un siglo y medio han producido las industrias de la minería y más recientemente las del turismo internacional.

En la última mesa dedicada a las lógicas de las clasificaciones, Louise Bénat Tachot, Université Sorbonne Paris IV, propuso una lectura de diferentes crónicas (Pedro Martyr, Fernández de Oviedo, López de Gómara, José de Acosta) que permite ver en las variaciones lexicales y las descripciones que las acompañan una manera de crear clasificaciones que tienen una relación directa con las categorías de bárbaro 
y policía. El espacio de la escritura y su correspondiente análisis ofrece un amplio abanico de estrategias a la hora de proponer una jerarquía de las sociedades indígenas.

Pascal Riviale, de los Archivos Nacionales de Francia CNRS-EREA (UMR 7186) dedicó su ponencia a las diferentes discursos raciológicos elaborados en Francia sobre el Perú a mediados del siglo XIX. Mostró cómo, con el desarrollo de las ciencias antropológicas en el siglo XIX, las instituciones científicas intentaron construir un discurso «objetivo» sobre las poblaciones (esencialmente indígenas) del Perú, a partir de materiales «positivos» que se les brindaba. En una segunda parte, el autor presentó el tipo de material difundido y su recepción tanto en Francia como en el Perú.

Pablo Perazzi (UBA, Instituto de Ciencias Antropológicas-CONICET) intervino enfocando el debate generado por las teorías sobre el poblamiento americano que han dominado la agenda antropológica argentina desde mediados del siglo XIX hasta bien avanzado el siglo XX. Inspiradas en fuentes, técnicas y saberes de naturaleza diversa, cultivadas por legos y profanos, las ideas acerca del acervo racial y cultural de los primitivos habitantes del nuevo mundo han dado lugar a complejas formulaciones que, aunque respaldadas por la pretendida neutralidad del discurso científico, se inscribieron en disputas que excedían ampliamente los muros de museos, bibliotecas y laboratorios. Detrás de las hipótesis americanistas se alzaba un vasto campo de tensiones entre la cultura letrada y el delineamiento de la identidad nacional. El propósito de la presentación fue abordar dichas disputas y tensiones a través de las principales teorías que alimentaron el debate americanista en el medio rioplatense.

Paula López Caballero, CNRS-CERI (UMR 7050), abrió un debate respecto a la manera en que se ha ido elaborando la frontera que distingue al «indígena» del «mestizo» y que a lo largo del siglo XX se volvió central o estructurante de las relaciones sociales en México. Al grado de considerarla, hoy en día, como una distinción «natural», evidente, que damos por hecho y que pareciera existir de manera objetiva o independiente de quién, dónde y cuándo se enuncie. Este debate aterrizó en el estudio histórico de las políticas indigenistas en su faceta más acabada institucionalmente en México: la acción promovida por el Instituto Nacional Indigenista (INI) en sus primeros años de actividad, específicamente sobre la creación del primer Centro Coordinador Indigenista (CCl) en Chiapas.

Guillaume Boccara del CNRS-Cerma/Mascipo cerró las actividades del coloquio con una discusión general en la cual subrayó lo siguiente:

En el curso de las dos últimas décadas, los trabajos etnohistóricos contribuyeron ampliamente a incentivar enérgicamente la investigación hacia el estudio de los fenómenos de etnificación y de etnogénesis. En cierta medida, podemos afirmar que el enfoque etnohistórico crítico, iniciado por los trabajos de Nathan Watchel en Francia y de diversos investigadores latinoamericanos, forma parte de nuestro patrimonio científico. Actualmente nuestro principal desafío es establecer un diálogo 
con los investigadores amerindios que escriben sus propias historias y producen nuevas memorias.

Conviene, entonces, interrogarse acerca de las articulaciones posibles entre la etnohistoria, en el sentido de disciplina, y las etnohistorias que abundan actualmente en la hora del multiculturalismo y de la búsqueda de reconocimiento.

No se trata de promover el populismo epistemológico sino de tener en cuenta las críticas de numerosos intelectuales indígenas con el fin de reincentivar una investigación histórico-antropológica que corre el riesgo de repetirse. Con el fin de evitar la apoteosis de la antropología histórica, debemos arriesgarnos hacia, lo que algunos ya nombran, la pluriversidad.

Gérard BORRAS 